\title{
Acute and subacute symptoms among workers in the printing industry
}

\author{
J BÆLUM,1' I ANDERSEN,2 AND L MøLHAVE ${ }^{1}$ \\ From the Institute of Hygiene, ${ }^{1}$ University of Aarhus, Aarhus, and the AMI, ${ }^{2}$ Copenhagen, Denmark
}

ABSTRACT The study population comprised 52 male printers and 52 controls. Each person was interviewed about job history, general health, and work-related symptoms. Symptoms from eyes and airways, neurological symptoms, and general symptoms were recorded. A lung function test and a measurement of the sense of smell were also carried out. The printers had significantly more eye, airway, and neurological symptoms than the controls; the main complaints being irritation of eyes, nose, throat, and a reduced sense of taste. The neurological symptoms were disorders of vision, vertigo, feeling of intoxication, and headache. Furthermore, abdominal pain and flatulence occurred more often among the printers. The symptoms showed no relation to age or job seniority, but neurological and general symptoms were related to shift work. No difference in lung function was found between the two groups.The printers had a slightly lower threshold of smell than the controls. Although the total load due to organic solvents and dust in the air was far below legal limits, the number and magnitude of symptoms experienced by the printers exceeded what is supposed when norms for workroom exposure are set. It is suggested that either the irritative effects of solvents are underestimated or the assumption of additive effects when great numbers of solvents are found does not hold true. A reduction of the number of solvents by eliminating the most toxic solvents or by using dyes without solvents is suggested.

Many different chemical products are used in the printing industry. In a study of 32 Danish printing industries ${ }^{1} 675$ different products were recorded; one industry used 151 different products. This multitude of chemical products with a high content of organic volatile solvents impedes the measurement and the control of the working environment in the printing industry, and makes it difficult to relate symptoms to exposures.

The aim of this investigation was to study acute and subacute work-related symptoms in printers exposed to these chemical products. At the same time solvents and dust in the breathing zones and the workroom air were measured. ${ }^{2}$

\section{Materials and methods}

The study population comprised 104 men aged 20-55-52 printers with a job of more than one year's seniority at the printing press and 52 controls.

The printers were selected at random from 254 printers working in the eight largest printing

Received 29 May 1980

Accepted 21 July 1981 industries in Aarhus, Denmark. One-third worked with letterpress printing, a process using only small amounts of solvents, one-third with off-set printing, (moderate use of solvents), and one-third with flexopress and rotagravure (large amounts of solvents). The controls were obtained via the national register, which for each worker drew six control subjects of the same sex, age ( \pm 3 years), and social group. The controls lived in the same street or area of town as the participating printers. A short questionnaire mailed to these controls included questions about job history, especially exposure to solvents and dust, smoking habits, consumption of drugs, previous and present diseases, height, and weight. Out of 280 questionnaires, 193 $(67 \%)$ were returned by those agreeing to participate.

The control subject best matching the printer was selected. Only control subjects without occupational to airborne pollutants and with smoking habits similar to those of the printers were chosen. For five printers no matching control was found in the first group of six, and another group of controls was selected for these five.

The investigations were performed by personal interviews. Each printer was interviewed at work. 
The questionnare covered job and general health histories, drinking and smoking habits, and consumption of drugs. Further questions covered airway, neurological, and general symptoms. The questions were based on the descriptions in toxicological textbooks ${ }^{3}{ }^{4}$ of the effects of solvents and the experience gained in a previous study of acute and subacute effects of solvents. ${ }^{5}$

The questions about airway symptoms covered irritation of the eyes, nose, mouth, and throat; cough; dyspnoea; frequency and duration of common colds; and changes in the senses of smell and taste. The neurological symptoms asked about were visual disorders, vertigo, periodical amnesia, feeling of drunkenness, increased reaction time, and reduced power of concentration without any consumption of alcohol. Questions about loss of muscular power and coordination and parasthesiae were also included. Finally, some questions covered general symptoms such as palpitations, sleeping difficulties, headache, fatigue, nausea, vomiting, abdominal pain, flatulence, and diarrhoea. For each question the frequency at work, after work, at weekends, and during holidays were recorded.

After the interview a lung function test was performed using a single breath spirometer (Vitalograph). Forced vital capacity (FVC), expiratory flow in first second $\left(F E V_{1}\right)$, and expiratory midflow $\left(\mathrm{FEF}_{25-75} \%\right)$ were measured. The sensitivity of the olfactory system was tested by estimating the threshold for an odorant (ethylvaleriate).

The matched control subjects were all visited in their homes within six weeks after the interview of the matching printer; they completed the same questionnaire and performed the same lung function and olfactometry tests as the printers.

The statistical methods used were described by Siegel. ${ }^{6}$ Wilcoxon's matched pair signed rank test and Mann-Whitney's U-test were used for comparing printers and controls and unmatched subgroups, respectively. The level of significance was $5 \%$ when using two-tailed tests.

\section{Results}

The quality of the matching of printers and controls has been investigated. No significant differences in height, weight, trade seniority, and general health were found between the two groups.

The table shows the average number of symptoms, and figs 1 to 3 show the distributions of symptoms at work for the two groups. Only symptoms experienced more than once a month were included. In all symptom groups the printers had more symptoms than the controls, and they had more symptoms at work than after work. The 18 letterpress printers had more airway-eye and general symptoms, and the 17 off-set printers had more airway-eye and neurological symptoms than their controls.

The symptoms experienced were irritations of the eye, nose, and throat; decreased sense of taste; visual disorders; vertigo; feeling of drunkenness; reduced power of concentration; and headache. Printers

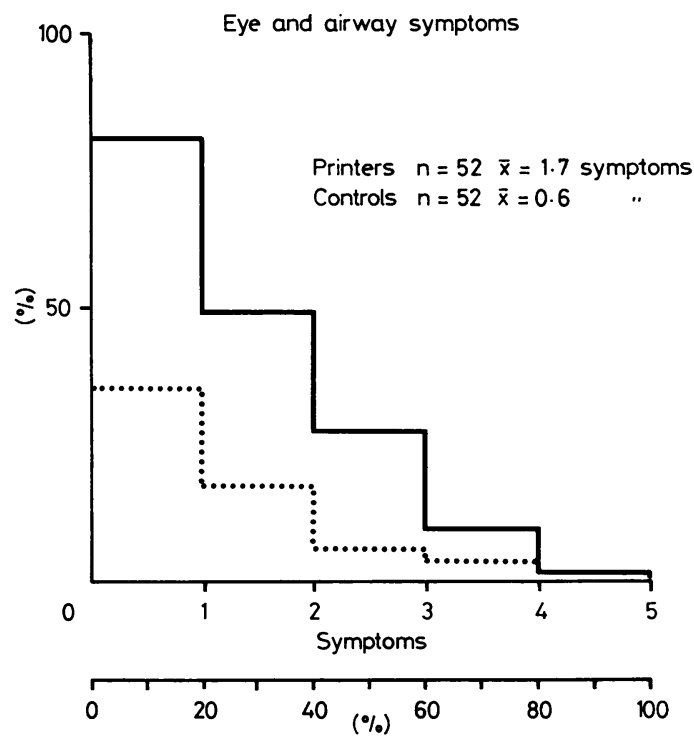

Fig 1 Respiratory symptoms. Figure shows cumulative distribution of symptoms at work. Only symptoms experienced more than once a month are included. -: Printers.

........... Controls.

Average number of symptoms among printers and controls. All the differences in symptom-rates between the printers and the controls are significant $(p<0.01$, Wilcoxon's test of pair differences)

\begin{tabular}{|c|c|c|c|c|c|c|}
\hline & \multicolumn{2}{|c|}{ Airway and eye symptoms } & \multicolumn{2}{|c|}{ Neurological symptoms } & \multirow{2}{*}{$\begin{array}{l}\text { General } \\
\text { symptoms }\end{array}$} & \multirow{2}{*}{$\begin{array}{l}\text { No of } \\
\text { subjects }\end{array}$} \\
\hline & At work & After work & At work & After work & & \\
\hline $\begin{array}{l}\text { Printers } \\
\text { Controls }\end{array}$ & $\begin{array}{l}1 \cdot 7 \\
0.6\end{array}$ & $\begin{array}{l}1 \cdot 1 \\
0 \cdot 5\end{array}$ & $\begin{array}{l}2 \cdot 3 \\
1 \cdot 1\end{array}$ & $\begin{array}{l}1 \cdot 3 \\
0.7\end{array}$ & $\begin{array}{l}2 \cdot 2 \\
1 \cdot 4\end{array}$ & $\begin{array}{l}52 \\
52\end{array}$ \\
\hline Maximum No of symptoms & 5 & 5 & 13 & 13 & 9 & \\
\hline
\end{tabular}




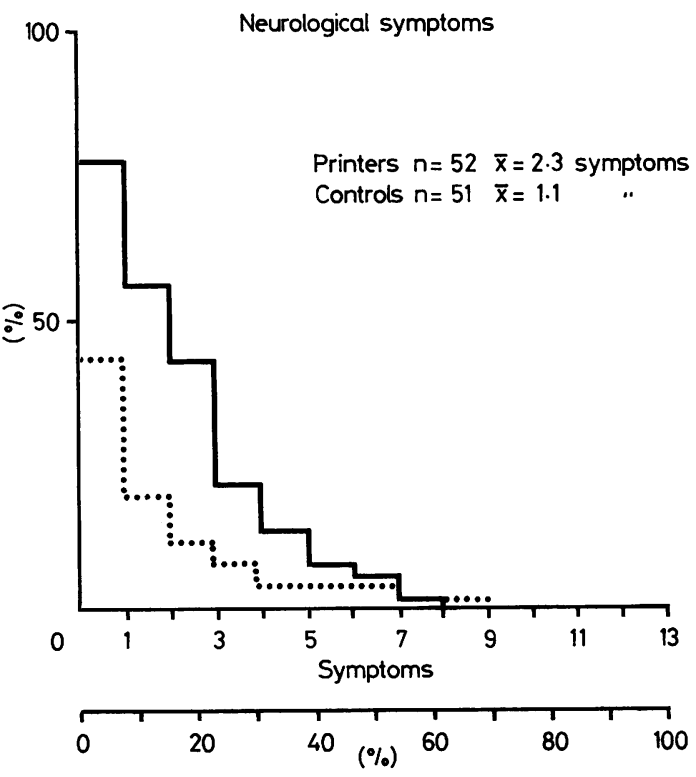

Fig 2 Neurological symptoms. For legends, see fig 1.

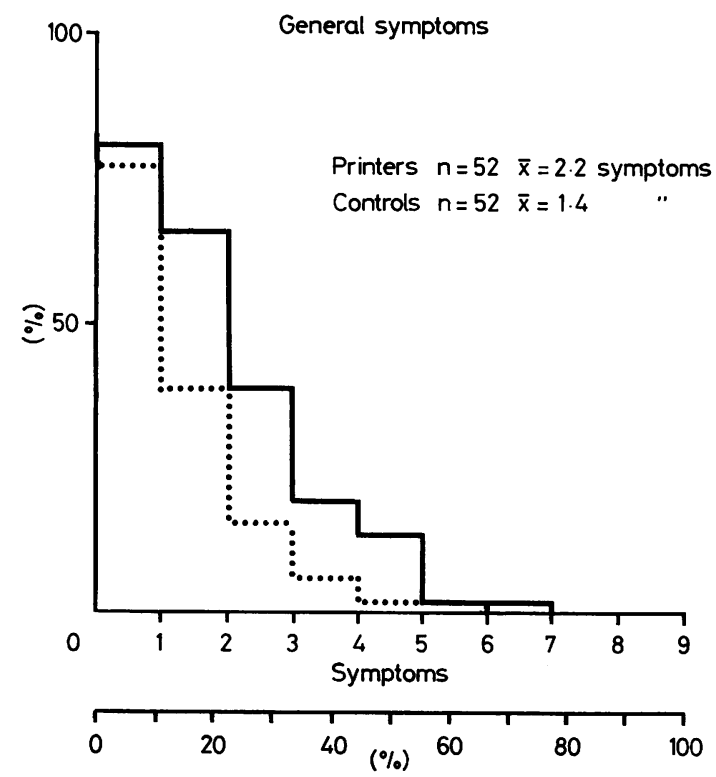

Fig 3 General symptoms. For legends, see fig 1.

experienced these symptoms more often at work than the controls (fig 4). After work only irritation of the nose and throat and visual disorders persisted with a higher frequency among printers than among the controls (fig 5).

Irritation of the eyes, nose, and throat is ex-

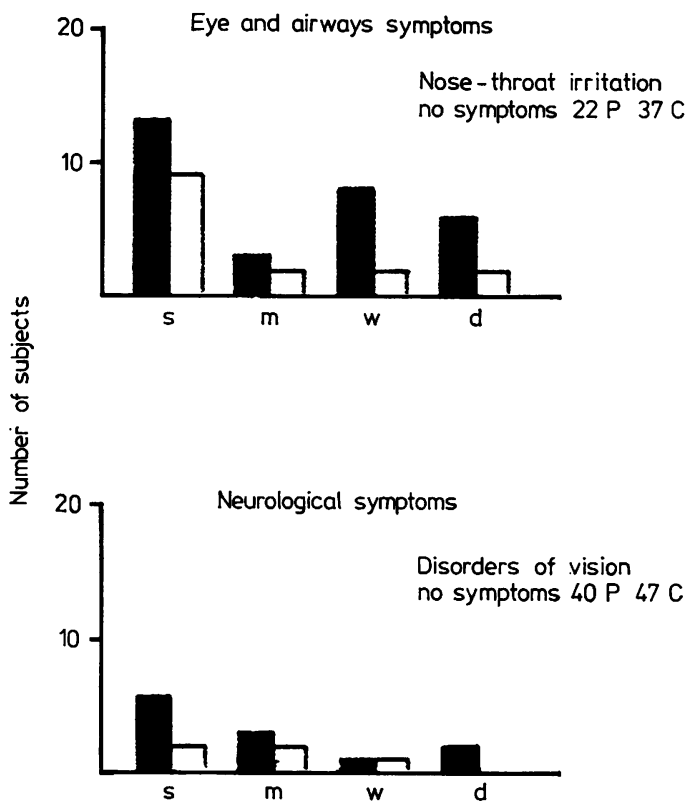

Fig 4 Number of printers and controls with symptoms at work. Frequency of symptoms is given in following categories: $d=$ daily symptoms, $w=$ symptoms one or several times a week, $m=$ symptoms one or several times a month, $s=$ symptoms less frequent than one day a month. Only symptoms with a significantly higher frequency in printers than in controls are included. Number of people without symptoms is also given in each diagram.

perienced daily or several days a week. The neurological symptoms and headache occur at greater intervals than the eye and airway symptoms.

Abdominal pains and flatulence were more frequent among printers than among controls. At weekends and during holidays the printers had fewer symptoms than after work. A comparison of the three subgroups of printers and their controls showed that most significant differences in symptoms were found among off-set printers, fewer among flexopress printers, and fewest among letterpress printers. The excess of symptoms was four, two, and one symptom, respectively.

The occurrence of symptoms was not related to age or job seniority, but smoking printers possibly had more airway symptoms than non-smoking $(\mathrm{p}=0.06)$.

The printers consumed more alcohol $(1.5$ alcoholic drinks a day), but symptoms were not related to the consumption. There was no difference in the consumption of drugs or in days lost through illness.

Forty printers worked two shifts or more com- 
Eye and airway symptoms
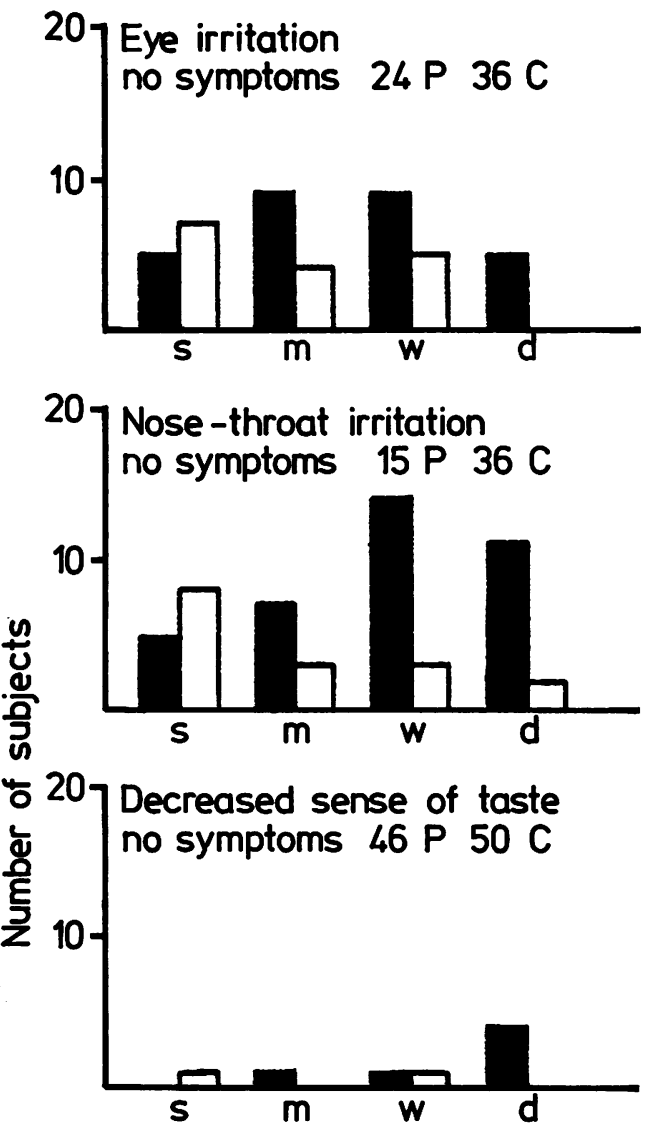

General symptoms

Headache

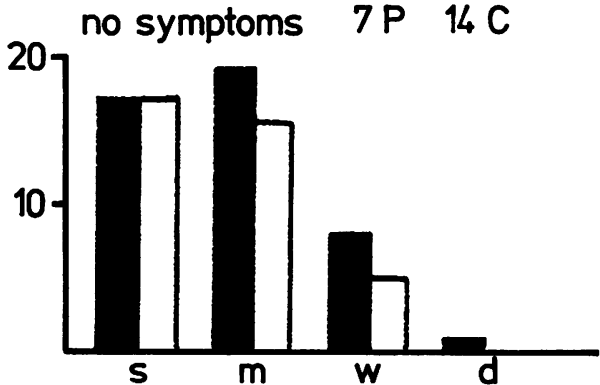

Neurological symptoms

${ }^{20} 7$ Disorders of vision

no symptoms $35 \mathrm{P} 46 \mathrm{C}$

$10-$

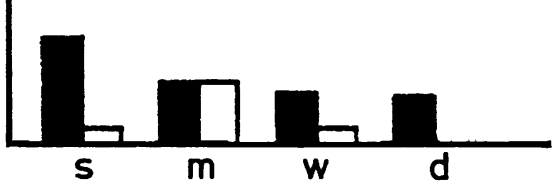

207 Vertigo

no symptoms $26 \mathrm{P} 42 \mathrm{C}$

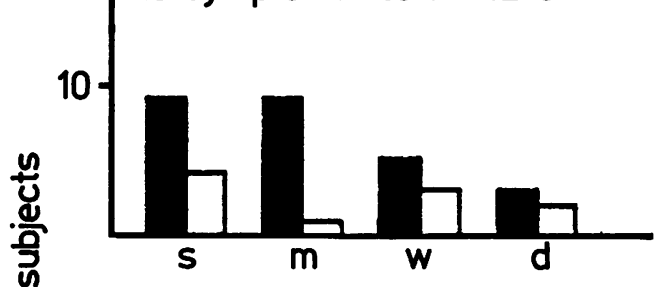

¿ 207 Feeling of intoxication

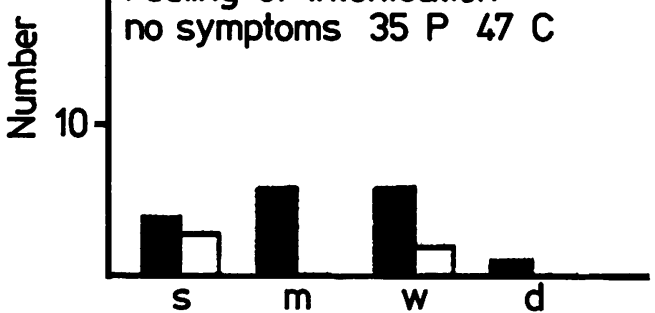

207 Reduced power of concentration no symptoms 38 . P $46 \mathrm{C}$

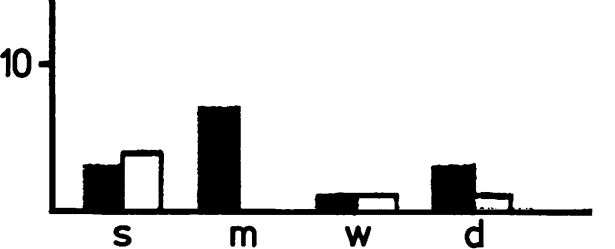

\section{Printers (P) $\square$ Controls (C)}

Fig 5 Number of printers and controls with symptoms after work. For legends, see fig 4.

pared with only seven of the controls. The 12 printers working one shift had fewer symptoms than printers working two or more shifts, the ratios being $0.7,0.5$, and 0.4 for respiratory, neurological, and general symptoms, respectively.

When comparing the symptoms of the shift 
workers and of the non-shift workers separately by the use of Mann-Whitney's U-test, significant differences are the eye and airway symptoms of the total group, and tendencies to difference were found in the letterpress and off-set groups.

No difference was found in the neurological and general symptoms between the 52 printers and their controls, while off-set printers had more of these symptoms than their controls.

It appears that general symptoms and neurological symptoms are related to shift work, whereas the work schedule has only a weak effect on eye and airway symptoms.

No difference was found between the two groups in the pulmonary function variables: FVC, FEV $\mathrm{FEV}_{1} / \mathrm{FVC}_{1}$, and $\mathrm{FEF}_{25-75 \%}$. The printers had a lower odour threshold for ethylvaleriate than the controls; in the subgroups this effect was found only among the letterpress printers.

\section{Discussion}

The aim of the study was to investigate acute and subacute symptoms in workrooms, and no attempt was made to investigate long-term effects on the general health status of workers in the printing industry. Symptoms with a significantly higher prevalence among printers than among the control group were considered job-related. The symptoms suggest that the main effect of the exposure during work in the printing industry is irritation of the eyes and of the airways. To some extent the nervous system and the general well-being of the workers are also affected. The effect on the nervous system is similar to that experienced after a small dose of alcohol, whereas complaints indicating more serious effects such as amnesia and peripheral neuropathia were not found. The complaints had the typical pattern for job-related symptoms; they decreased in severity after work, and disappeared at weekends and during holidays, when the prevalence of symptoms was identical among printers and among controls.

Considering the effect of shift work, only a significantly higher prevalence of eye and airway symptoms among the printers remained. In the subgroups only a significantly higher prevalence of neurological and general symptoms remained among off-set printers. We conclude that the best subjective indicator for an acute exposure to dust, gases, and vapours in the printing industry thus appears to be eye and airway symptoms. These symptoms are not accompanied by an increase in the frequency of airway infections (including common colds) or changes in respiratory parameters. Repetitive exposure to solvents has been reported to bring about hyposmia or anosmia. ${ }^{7}$ In this study the determination of the odour threshold for ethylvaleriate did not show such changes in odour perception.

On the day of the interview the concentrations of dust and organic vapours were measured in the breathing zones of the printer during normal work. ${ }^{2}$ Thirty-two different substances were found, seven per sample on average. Toluene, ethanol, and decane were found most often. Assuming additional effects of the substances ${ }^{8}$ the average hygienic load was 0.36 ranging from 0.0 to 1.0 .

The preface to the list of TLVs says: "TLVs refer to airborne concentrations of substances and represent conditions under which it is believed that nearly all workers may be repeatedly exposed day after day without adverse effect. Because of wide variation in individual susceptibility, however, a small percentage of workers may experience discomfort from some substances at concentrations at or below the threshold limit; a smaller percentage may be affected more seriously by aggravation of a pre-existing condition or by development of an occupational illness."

In this investigation where the concentrations of the atmospheric pollutant were all below the TLV for mixtures, symptoms were nevertheless present in a number and a magnitude that definitely exceed what is intended in the assumptions for the TLVs' setting.

In the study there is no indication of the reason for this unexpected lack of connection between exposure and symptoms. Possible explanations are either that the irritative effects of solvents are underestimated or that the TLVs used in combinations (assuming additive effects) underestimate the effects. An extensive Finnish study ${ }^{9} 10$ supports these suggestions. Car painters exposed to low concentrations of a mixture of solvents showed an excess of symptoms and signs of intellectual impairment by comparison with a control group.

The nature and frequency of the symptoms experienced by the printers indicate the necessity of a decreased exposure to atmospheric pollutants in the workroom. An improvement of the working conditions may be obtained by a decrease in the amounts of solvents used and by improving the ventilation. In addition, the number of solvents should preferably be reduced by eliminating the more toxic substances. This would also facilitate the daily control of the atmospheric environment by simple methods.

The study was supported by the Danish Medical Research Foundation. We are grateful to the Printers' Trade Union, The Employers' Association, 
and the industries concerned for having made the study possible.

\section{References}

${ }^{1}$ Andersen PE, Boserup B, Seedorff L, Sørensen F. Chemical products in the printing industry. Copenhagen: Institute for Medical Chemistry, 1977. (In Danish.)

${ }^{2}$ Mølhave L, Bælum J. Pollution components in the air in graphic workshops. Ugeskr Lager 1979;141:3187-92. (In Danish.)

${ }^{3}$ Browning E. Toxicity and metabolism of industrial solvents. Amsterdam: Elsevier, 1965.

+ Casarett LJ, Doull J. Toxicology. New York: Macmillan, 1975
${ }^{5}$ Laier M. Investigation of symptoms in house painters at their work sites. Ugeskr Lager 1976;138:1225-30. (In Danish.)

${ }^{6}$ Siegel S. Nonparametric statistics. 1st ed. New York: McGraw Hill, 1956.

${ }^{7}$ Emmett EA. Parosmia and hyposmia induced by solvent exposure. Br J Ind Med 1976;33:196-8.

${ }^{8}$ American Conference of Governmental Industrial Hygienists. Threshold limit values for chemical substances in workroom air. Cincinnati, Ohio: ACGIH, 1978.

${ }^{9}$ Hänninen $H$, Eskeminen $L$, Husman $K$, Nurminen $M$. Behavioral effects of long-term exposure to a mixture of organic solvents. Scand J Work Environ Health 1976; 4:240-55.

${ }^{10}$ Husman K. Symptoms of car painters with long-term exposure to a mixture of organic solvents. Scand $J$ Work Environ Health 1980;6:19-32. 
sweating, and faintness, also within five minutes of a dose of 5-10 mg of sodium azide.

In our report three technicians ingested some $\mathbf{4 0}$ mg sodium azide and developed symptoms that disappeared quickly and completely. The fourth who ingested only some $20 \mathrm{mg}$ was affected to a lesser degree. The male technician who presented a clinical picture of myocardial ischaemia ingested some $80 \mathrm{mg}$ of sodium azide. This patient had no knowledge at that time of the illness of the others, or that his symptoms were due to sodium azide.

The severity of symptoms was thus related to the dose ingested in four of the patients. In the technician with a dose of $80 \mathrm{mg}$, however, symptoms of myocardial ischaemia developed, and these have not previously been described. The initial rapid recovery after a few hours is not inconsistent with the view that this was a direct result of the sodium azide, although the recurrent episodes of chest pain with admission to hospital suggest an added psychogenic element.

\section{References}

' Sutton WL. In: Patty FA, ed. Industrial hygiene and toxicology. 2nd rev ed. Vol 2. New York: Interscience Publisher, 1980:220-8.

${ }^{2}$ Black MM, Sweifach BW, Speer FD. Comparison of hypotensive action of sodium azide in hypertensive patients. Proc Soc Exp Biol Med 1954;85:11-6.

${ }^{3}$ Richardson SGN, Giles C, Swan CHJ. Two cases of sodium azide poisoning by accidental ingestion of isotone. J Clin Pathol 1975;28:350-1.

4 Gobbi A. Re casi di intossicazione da sodio-azide. Med Lav 1967;58:297-300.

s Burger E, Bauer HM. Akuter Vergiftungsfall durch versehentiliches Trinken von Natriumazidlosung. Archiv für Toxikologie 1965;20:279-83.

- Kozlicka-Gajdzinska H, Brzyski J. A case of fatal intoxication with sodium azide. Archiv für Toxikologie 1966;22:160-3.

${ }^{7}$ Emmett EA, Ricking JA. Fatal self-administration of sodium azide. Ann Intern Med 1975;83:224-6.

\section{Scipione Caccuri Prize}

The "Fondazione Clinica del Lavoro" has established an International L20 000000 (twenty million Italian lire) prize in memory of Professor Scipione Caccuri, the former director of the Institute of Occupational Medicine at the University of Naples. The prize will be assigned to a previously unpublished work making an original contribution in the field of occupational and industrial medicine, physiopathology, and hygiene. Texts written in Italian, French, English, German, or Spanish considered meritorious will be published in a special number of Giornale Italiano di Medicina del Lavoro. Such texts should be addressed to: Segreteria della Fondazione Clinica del Lavoro, Via Boezio, 26, 27100 Pavia (Italy) and should be received by 31 December 1983.

\section{Correction}

Acute and subacute symptoms among workers in the printing industry (February 1982)

Figures 4 and 5 have been interchanged: figure 4 is the figure on page 73 while figure 5 is on page 72 . 